\title{
The Leadership Role of the Education Specialist in the South African TVET Sector
}

\author{
Jan Andries Pretorius \\ Deputy Principal: Corporate services at Gert Sibande TVET College, \\ 18a Beyers Naude Street, Standerton, 2430
}

\begin{abstract}
The Technical Vocational Education and Training Colleges in South Africa is a relatively new phenomenon. The colleges in their current format was implemented about 15 years ago. The level of performance of these institutions are overall not at the required level, with some colleges performing better than other.The performance of these institution has a direct impact on the economic development of South Africa as colleges are not producing the necessary vocational and technical skills. As part of the improvement processes there are numerous developmental programmes for lecturers, campus managers and staff. The one neglected area is the development of the Education Specialist. The Education Specialist is at the coal face of academic delivering, as well as the first level management. With the development of Education Specialist leadership skills, as well as involvement in corporate planning, there will be a substantial improvement in student performance. This will have a direct impact on the economic situation of the country.

Keywords: Education Specialist, Academic middle manager, Technical Vocational Education and Training Colleges
\end{abstract}

DOI: $10.7176 / \mathrm{EJBM} / 13-6-16$

Publication date:March $31^{\text {st }} 2021$

\section{Introduction}

The Technical Vocational Education and Training (TVET) Colleges in South Africa was previously known as Technical Colleges. In 2004 the process started to amalgamate the 150 Technical Colleges into 50 TVET Colleges. The merger was based on the geographical vicinity of institutions, and boundaries for Regional municipal areas, resulting in at least one TVET College per region. (Buthelezi, 2018).

The formation to the TVET system brought many serious challenges. This is echoed by Kraak, Paterson \& Boka (2016) when they state: "The TVET Colleges seem to embody a fundamental institutional enigma - despite multiple changes intended to improve the quality and efficiency of the colleges, they are still viewed as underperforming."

Various initiatives were launched to increase the performance of students as well as the overall performance of TVET Colleges. Balkrishen \& Mestry (2016) studied the professional development of campus managers and wrote extensively on how effective leadership of campus managers in a TVET college can influence student achievement.

Kraak, Paterson \& Boka (2016) proposed an integrated framework for College transformation, that includes student performance, lecturer development and peer tutoring.

In all the above mentioned studies and proposals, one critical aspect is not mentioned, and that is the role of the academic middle manager, or Education specialist (ES), in improving TVET College performance.

When considering the focus of Balkrishen \& Mestry (2016) on campus manager development, as well as the focus of Kraak, Paterson \& Boka (2016) on Lecturer development and systems like Peer tutoring, there is a gap in the academic structure that is not attended to in terms of development, namely the Education specialist (ES) level

\section{What is an academic middle manager?}

When considering the role of academic middle managers, known as Education Specialists, in the South African TVET College sector, it is crucial to firstly identify what is considered as a middle manager.

Gleeson \& Shain (1999) refers to educational middle managers as individuals who assume managerial responsibility for aspects such as co-ordination of courses, people management and budgets.

Briggs (2001) describes middle management as a hierarchical structure that assumes a downward flow of authority. Instructions are given in line with what the leader in the authoritarian role wants.

The two definitions above view a more traditional role of the middle manager. It is also very academic descriptive that makes it difficult for middle managers to exactly understand what is expected from them in their day-to-day role at Colleges.

The role of the academic middle manager changed considerably over the last decade. This can be seen in the definitions from Chen et al (2010) and Meek et al (2010) that was developed ten years later.

Chen et al (2010) indicates that the term middle management refers to managers who typically head a function, team or office and supervise day-to-day activities and other operations. They are located below top managers. 
The definition from Chen et al (2010) is easy understandable and describe numerous factors clearly, namely what the position entails, daily operations and placement in the organisations structure.

Meek et al (2010) aligns the role of the middle manager with the changes that is noticed in Higher Education over the last couple of years. Meek et al (2010) describes middle management as using various means such as mission articulation, strategic planning, evaluation and commercial marketing and higher education managers are to ensure that their institutions become more entrepreneurial adaptive and commercially responsive.

If the definitions by Chen et al (2010) and Meek et al (2010) are considered together it gives an easy understandable description of the role and position of a middle manager in an organisation. It also gives a clear indication that the traditional role of an academic manager has changed and that aspects like mission articulation to staff and students, strategic planning and commercial marketing of institutions are critical aspects of the role that an academic middle manager plays in the modern academic institution.

\section{Role of the academic middle manager}

Numerous studies were conducted over many years trying to establish exactly what the role of an academic middle manager is. Briggs (2004) defined five aspects of the middle manager's role in Further Education, namely that a middle manager is a corporate agent, an implementer, a staff manager, liaison and lastly a leader.

Van der Westhuizen (1998) emphasises that there is a number of leadership skills and roles that are important for institutional leaders of academic institutions. The most important aspects mentioned by van der Westhuizen (1998) is an institutional leader has vision, can define reality, have a value system, can set direction and align people.

When comparing the role of education middle managers, as explained by Briggs (2004) and van der Westhuizen, (1998) the role of an Education Specialist can be summarised as:

1. A person that represents the best interest of the institution (corporate agent)

2. A person with vision of what is to be achieved in the specific academic unit responsible for and who can implement his/her vision linked to the reality of the current situation and set the direction in successful implementation

3. Take leadership in his/her department by giving leadership to sub-ordinates reporting to him/her

These aspects are critical important and therefore needs to be discussed in more detail

\subsection{Represents the best interest of the institution}

When it is referred to as the academic middle manager representing the best interest of an organisation, it is imperative to understand that it can be done in a positive way, but also in a negative way.

When academic managers have the best interest of an organisation at heart they see themselves as protectors of time, mental states and a culture needed to conduct professional academic work. (Gjerde, 2019).

Gjerde (2019) is however also realistic when going further and describes that there will be circumstances where the academic middle manager has to not only have the best interest of the organisation at heart, but also the best interest of the subordinates reporting to the middle manager. Gjerde (2019) explains this point by indicating that the middle manager sometimes has to protect the subordinate from what it seems as unnecessary and / or damaging initiatives and information from top management above, in order to allow for good professional work to take place.

The aspects as Gjerde (2019) described is critical for a middle manager in order to uphold the interest of the organisation. If this is not able to take place, the academic middle manager will not be able to effectively uphold the interest of the organisation.

Harding (2014) emphasises this point when indicating that the academic middle manager may outwardly express enthusiasm about processes while covering up profound anxieties, so that they merely comply with changes rather than promoting them enthusiastically.

It is very difficult for an academic middle manager to have the best interest of the organisation at heart if they do not believe in what needs to be implemented and managed. However, many will still endeavour to promote the ideas.

In the description above it is clear that the academic middle manager must promote the best interest of the organisation, if he/she do not fully belief in the in the processes or in the initiatives from top management.

Unfortunately, it is also possible that there will be the academic middle manager who will actively work in harming the interest of the organisation. Middle managers may re-interpret strategic plans and may actively resist implementation. (Harding, 2014).

An academic manager that actively resist plans of the institution, do not have the best interest of the institution at heart. Even if the academic middle manager does not fully belief in the activities that happens, they should instill the mental state of subordinates and promote a culture of conducting yourself professionally as described by Gjerde (2019). 


\subsection{Vision development and implementation.}

When considering the role of an Education Specialist as indicated above, there is a clear leadership role, by having a vision, but also managerial role by implementing the vision.

Because of the hierarchical culture of DHET, most Education Specialists alternates between the role of leader, but follower as well. In this regard Gleeson \& Knights (2008) raise a critical aspect of the Education Specialist's role by indicating that followers should be discouraged to continuously look to leaders to provide the answers. Leaders should expose followers to changing circumstances and asking tough questions to allow followers to produce their own solutions.

Vision development and implementation is part of a strategic thinking process. Wootton \& Horne (2010) described vision development as a continuous process that can be illustrated as below:

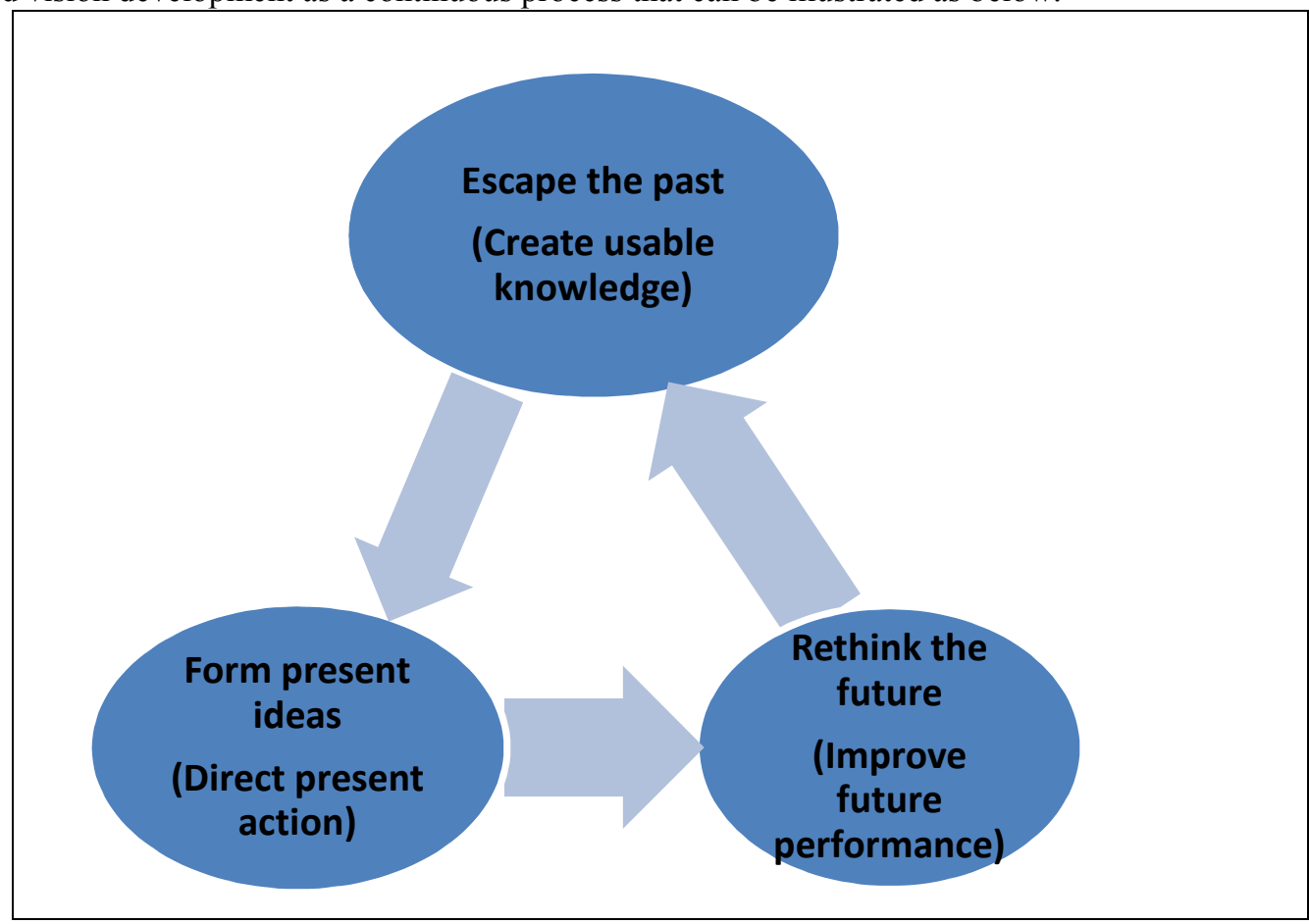

Figure 1: Vision development as a continuous process

A clear process transpires from the above illustration namely, learn from past situations and take the knowledge to form ideas and direct your current situation. The next step is to evaluate all of the information gathered from the past and the current situation. This is then used as the basis to develop a vision to improve future performance. Developing and implementing a vision is not a once of process. It is a continuous process.

Developing and implementing a vision is a futile exercise if the middle manager does not know what criteria a vision needs to meet to be effective. Wittman \& Reuter (2008) explains the following four criteria:

1. A vision should be trendsetting: It should show a clear direction.

2. A vision should be convincing: It should address positive values, is intuitive and credible

3. A vision should be realizable: The vision should be challenging, but not Utopian. It must be achievable

4. A vision must be concise: It should be easy for everyone to understand.

If a vision does not meet these criteria, it becomes nothing else but a wish list or dream that a person hopes will happen.

\subsection{Taking a leadership role.}

Middle managers are placed in a pivotal role between central management predilections and academic values and control (Meek et al., 2010).

The reality however is that many times the academic middle manager is not able to take full leadership in his/her department. Meek et al (2010) states it clearly that in many higher education institutions the middle manager is seen more as academics than managers.

This is a matter that needs to managed carefully by senior management of an institution, if the institution wants to be successful in service delivery and leadership. The best way to learn leadership skills, and to be able to implement them is through experience. Gleeson \& Knights (2008) captures this matter perfectly when they say that leaders should expose followers to changing circumstances and asking tough questions to allow followers to produce their own solution. This also emphasises the difficult position the middle manager is in, namely that he/she 
must be given the opportunity by senior management to lead his/her team, but also give subordinates the opportunity to learn leadership skills.

The best way to describe the need for an academic middle manager to take leadership in his/her department comes from Meek et al. (2010) when they explain that to a large extent the success of academic institutions rest on effective leadership.

\section{The impact of the organisational environment on the performance of the academic middle manager}

Another critical aspect to consider is the organisational environment in which the Education Specialist needs to function. This can also be described as the organisational culture of the institution. This organisational culture will be different in each of the fifty TVET Colleges in South Africa. Some Colleges will have a strong focus on support and academic achievement, and others may be on the verge of being dysfunctional.

Glover et al (1999) describes the two extreme environments. They indicate that subject leaders in traditional institutions will play little role in the development of the institution, if they do not have management responsibilities affecting the whole institution. On the other side of the scale will institutions that have an atmosphere of collegiality and trust inspire middle managers to enhance and empower their work at a level benefitting the whole institution.

The above statements indicate again that an institution that trusts their middle managers and make them feel valued will allow these middle managers to be more successful in their role. Unfortunately, the bigger an institution or College is becoming, the less likely an academic middle manager, or Education Specialist will be able to make a significant impact on the whole institution. This is emphasised by Blasé (1995) when indicating that the wholeinstitution collegiality featured in effective schools, where the middle-manager act as transformational leaders, becomes problematic in large institutions. To further emphasise the impact of organisational culture, Leithwood et al (2011) states that the institutional culture must be one in which customs and values foster success for all, the boundaries are set, known and agreed upon by everyone.

The experience of Education Specialists in the organisational culture will shape the way in which decisions are made. Bennet (1995) explains how managers uses experience and personal values to formulate an "assumptive world" or "theory in use" which will guide the middle manager in decision making. This ultimately translates in how the Education Specialist will give provide leadership to the specific department.

Briggs (2001) identified certain elements in a College environment that will enable managers to participate in higher level leadership, namely:

1.The support, or lack of support, from senior management

2.Events and systems that allow middle managers to participate in corporate planning

3.Effective communication of data and information for decision making

4.Opportunities for peer support. This may be internal or external support

5.Acknowledging and respecting the subject expertise of the middle manager

6.The opportunity to delegate responsibilities.

The aspects mentioned above forms another part of the basis for an Education Specialist to be an effective leader and will be discussed in more detail.

\subsection{Support from senior management}

The relationship and support of the senior management of an organisation is imperative for the success of the academic middle manager.

It is also imperative that both senior management and the middle manager understand their role in an organisation. Top management is responsible for strategy formulation and the middle manager's role is strategy implementation (Raes et al., 2011). It should however be remembered that strategy formulation and strategy implementation are not separate functions.

In this regard we also need to refer back to the definitions of an academic middle manager as supplied by Meek et al. (2010) and Chen et al (2010). It is important to understand that the middle manager is placed under the senior management, but in the changing environment of higher education globally, no institution can be successful if the middle manager is not strategically involved in the institution.

Therefor if the Education Specialist does not play a role in strategy formulation, they will not be able to successfully implement strategy. If middle management is only implementers of strategy, and not involved in any strategy formulation process, it will create dissatisfaction.

The relationship between senior management and middle management will play a crucial role when staff is dissatisfied. Dissatisfied employees have two options: They can exit the system or voice their dissatisfaction. Middle managers will only voice their dissatisfaction if they belief that management will listen and take appropriate action (Fernando, 2017)

This emphasises the importance of the supportive role of senior management to assist the middle manager in achieving the necessary outputs, namely good student performance. 


\subsection{Participation in corporate planning}

As indicated by Meek et al (2010) there is a changing organisational environment where the academic middle manager plays an ever increasing role in the strategic planning of an institution. Raes et al. (2011) echoes this aspect by indicating that both top management and middle managers have an important influence on strategy formulation and implementation.

Tarakci et al (2018) emphasises this as well by describing that middle managers are essential actors in strategic renewal. Their unique positions offer insight into operations alongside knowledge of strategy.

The above descriptions of the involvement of middle managers are specific true in the South African TVET sector. The Education Specialist is the operational level where strategic decisions are implemented. Flowing from the discussion above and the South African TVET sector context, the question is exactly what the roles should be between top management and Education Specialists.

There is no clear answer to these roles and Raes et al. (2011) echoes this by stating that surprisingly little is known about specific functions of the top management and middle managers interface in strategy formation or how these two echelons achieve alignment between their activities.

The above statement from Raes et al. (2011) is a worrying fact, as the co-operation between senior management and middle management is the vehicle to success in the higher education sector, and even more so in the South African context, with the ever changing environment that TVET colleges needs to deal with.

\subsection{Effective communication and decision making}

The importance of communication between top management and middle managers are applicable to every institution. No aspect of any institution, or TVET College in the South African context, can be successful if there is no effective communication. The information received from all echelons in the College allows for effective decision making.

To achieve alignment between top management and middle managers, it is crucial that both parties be able to integrate the information and perspectives from both sides and use this integration as basis for their respective activities (Raes et al., 2011).

\subsection{Opportunities for peer support}

No person can act as an individual. This is even more true for the Education Specialist in their role to provide guidance and support to staff and students and implementation of numerous policies.

Middle managers can understand their middle managerial identity through exploring the identity work they undertake while talking to each other (Harding, 2014).

Harding (2014) raises some crucial points top management must take cognisance of. Firstly, middle managers are not just a position, it is an identity as Education Specialist and secondly, that the work they do are identity work. This entails that the work should be directly linked to their identity as Education Specialists.

The peer support that is crucial for Educational Specialists are not confined to their respective institutions. As middle managers perform their strategic roles, it also extends into their horizontal relationships. These middle managers are also important mediators across organizational boundaries (Rouleau \& Balogun, 2011).

In the South African context, the above is even more crucial. The TVET College system is relatively new. To provide the opportunity for peer support in the institution is very helpful, but even more critical is the opportunity to engage outside of individual Colleges. This will allow Education Specialists from better performing Colleges to assist others in increasing quality teaching and learning in these Colleges as well.

\subsection{Subject expertise of the Education Specialist}

Many authors including Gjerde (2019), Meek et al (2010), Gleeson \& Knights (2008), Leithwood et al (2011), Raes et al (2011) and Chen et al (2010) links the subject expertise of the academic middle manager to his role as leader and contributor to the strategic planning and strategic implementation processes.

Professionals are defined as individuals who have the ability to do their work as they see fit, on the basis of their own sense of knowing how to do it (Fernando, 2017).

If all the above information is considered it is crucial that top management of any institution acknowledge and respects the subject expertise of the Education Specialists. This brings the aspect of practical implementation that the top management may not always understand, or have the experience of.

\subsection{Delegation of responsibilities}

For many individuals it is extremely difficult to delegate certain responsibilities.

Delegation is not about giving op your authority, power, control, accountability or your responsibility to help your employees to succeed (Dittmer \& McFarland 2007).

Delegation is a dual process where top management can use it as a development tool to increase leadership qualities of Educational Specialists. However, it also allows Education Specialists the opportunity to develop 
subordinates.

Top management of institutions sets the tone for delegation (Dittmer \& McFarland, 2007). When delegating you need to give people the permission to make the delegated task their own (Smart, 2003).

The authors quoted above make it clear that delegation is not simply giving a subordinate a task that the manager do not want to do. When the Education Specialist delegate it is crucial to do it in such a way that the person takes up the opportunity and that you guide the process. Delegation requires the manager to be strong, supportive and resilient. If all goes well, your team members should get the credit. If it goes wrong, the manager must accept responsibility and accountability

\section{Professional development of the Education Specialist}

The role of management training is to provide templates on "how to become managers". It also illustrates how complex it is to be and to become a manager (Andersson, 2010).

Many times top management take it for granted that an academic professional will just know how to be a good Education Specialist as well. This is however not the case.

The changes to academic careers, coupled with increased accountability across the sector have meant that the role of the academic middle manager is also changing and becoming increasingly complex. It seems that managers are increasingly struggling to adequately manage key aspects of their roles (Floyd 2012).

Stronge, Richard \& Catano (2008) describes that the ultimate goal of professional development is to increase student learning. Cloete, Perold \& Papier (2012) also describes how these actions can improve student achievement.

The challenge for organizers of management training is to bridge the "being a manager" part of training and the "becoming of a manager" in practice (Andersson 2010). This statement brings two crucial aspects namely that management training can teach the Education Specialists certain management and leadership skills. However, you can only become a manager and leader by having the opportunity to practice and develop this in the work environment. The theoretical and practical component of Education Specialist development is crucial.

Terblanche (2017) developed potential modules and elements for curriculum leadership, which would benefit Education Specialists greatly, The module focusses on leadership and curriculum changes. It also deals with change management strategies. Terblanche (2017) also considered training on different leadership styles that will lead to curriculum change.

Unfortunately, there is no official development program available through DHET for Education Specialists. This results in these individuals either not receiving any form of staff development, or they take responsibility for their own development through studies at Universities, or lastly some colleges will be running their own development program for these individuals.

\section{The impact of the Education Specialist}

The reason for creating a position for Educational specialists, is that they should have a specific impact as academic middle managers. There are numerous duties that the Education Specialist is responsible for in order to manage and control his/her department.

The impact of an Education Specialist should however, reach further than simply do what is on his/her job description. One of the most critical impacts is effective communication. Bennet (1995) describes that middle managers can be a creative force by controlling and influencing the flow of information.

Early (1998) also describes the impact that the Education Specialist can have on the strategy of the institution. Early (1998) has two conditions for the above, namely the appropriate organisational culture and the willingness of the individual. The last condition is a critical point, as an individual that is not willing to participate in strategic discussions, only becomes a person that does what he/she is told to do. This Education Specialist will also not have a vision of where he/she wants to take his/her department in the bigger scope of institutional performance.

The impact that the Education Specialist can have on an institution is in many cases limited. Numerous factors play a role. Briggs (2001) identified two major concerns that impact on the performance of academic middle managers, namely the size and complexity of their role and secondly the lack of role definition.

Early \& Fletcher-Campbell (1998) supports the above concern by stating that role uncertainty and role clarity are obstacles to managing effective departments. This is also a factor causing stress and leading to reduced effectiveness under academic middle managers, or Education Specialists in the South African context.

\section{The Education Specialists view of their role academic middle managers}

Most importantly Education Specialists must realise what it is like to be genuinely middle in terms of identity, that is, who am I and what is my role, that is what should I do in this middle? (Gjerde, 2019).

The way in which academic middle managers view themselves have been researched internationally, by numerous researchers. Lumby (2001) found that the majority of academic middle managers do not see themselves as leaders. Bennis (1998) describe the role of academic managers as doing things right, not necessarily doing the right thing. The feeling is such that the academic middle manager is doing what is expected, and doing it good, 
but not necessarily doing what is the right thing for his or her department.

Education Specialists are in the difficult position that they stand in two different worlds. They return from the boardroom just to communicate the details of decisions that was taken by the Principal (Ainley \& Bailey, 1997). The role of the academic manager is acknowledged as being complex and difficult (Floyd, 2012).

Robertson (2005) explains how the academic middle manager is always in reactive mode. They have to implement policies they feel they do not have ownership of, they have to become experts in areas they were not trained in, yet they need to take the responsibility for all of this. Raes et al. (2011) emphasises the previous point by alluding that if middle managers are low in participation they see themselves as passive executors of policies and only focus on their own business units.

However, what is clear is that academic middle managers can excel in their role if supported by senior management. Graham (2016) conducted a small scale study in performance management of academic managers. One of the participants described how they are empowered, as the Dean enables then to carry out their duty with his full support. When middle managers are interested and actively engaged in strategy formulation and implementation they see themselves as having an important role (Raes et al., 2011).

If Education Specialists are actively involved in strategy formulation and implementation and are not merely implementers, their view of their role is positive and they feel that they are contributing. If not, many Education Specialists will feel that they do not make a difference and that the pressure of the role is too much. Some academic middle managers feel that the pressures associated with their role outweighs the perceived benefits of the position (Floyd, 2012).

\section{Suggestions}

- Education Specialists must be given the opportunity to be involved in corporate planning in their respective institutions

- Programs must be established to allow Education Specialists to develop their identity as middle managers

- Senior management must acknowledge the subject expertise of Educational Specialists

- Establishment of developmental programmes that will allow Educational Specialists to take leadership in their respective departments

- The establishment of peer support groups will allow Education Specialists to deal with leadership matters at their respective level, as well as sharing best practices.

\section{Conclusion}

The Education Specialist in the South African TVET sector is the middle point of service delivery, namely to manage the academic delivery to students. The efforts of these managers greatly determines the success of academic service delivery. Therefor it is crucial that the TVET sector in South Africa takes collective responsibility to develop the Education as academic middle manager. This development involves both the ability to take charge of their departments, as well as the ability to understand and implement the role of senior management in their respective institutions. If the Educational Specialist is developed and are able to embrace their role as academic middle manager, the result will be visible in the performance of the staff and students in their departments.

\section{Bibliography}

Ainley, P. \& Bailey, B. (1997). The business of Learning: staff and students experience of further education in the 1990 's. London: Cassel

Andersson, T. (2010). Struggles of managerial being and becoming. Journal of Management development. 29(2): 167-176. Doi:10.1108/02621711011019305

Balkrishen, P. \& Mestry, R. (2016). The leadership role of campus managers to improve student achievement in Colleges. South African journal of Higher Education 30(5), 28-47. Doi:10.20853/30-5-571

Bennett, N. (1995). Managing Professional Teachers: middle management in primary and secondary schools. London: Paul Chapman

Bennis, W, G. (1998). Why leaders can't lead. San Francisco, CA: Jossey-Bass

Blasé, J. (1995). The Micro political orientation of Facilitative School Principals and its effects on teacher's sense of empowerment. Paper presented at the American Educational Research Association conference. San Francisco. April

Briggs, A, R, J. (2001). Academic middle managers in further education: reflections on leadership. Research in Post-Compulsory Education 6(2), 223-236. Doi:10.1080/13596740100200096

Briggs, A, R, J. (2004). Middle managers in further education colleges: The "new professional". Journal of Education Administration 42(5), 586 - 600

Bryman, A. (2007). Effective leadership in higher education: Summary of findings. London: Leadership foundation for Higher Education 
Buthelezi, Z. (2018). Lecturer experiences of TVET College challenges in the post-apartheid era: A case of unintended consequences of educational reform in South Africa. Journal of Vocational Education \& Training. Doi:10.1080/13636820.2018.1437062

Chen, C., Berman, E. \& Wang, C. (2010). Middle managers' upward roles in the public sector. Sage journals. Doi:10.1177/0095399714546326

Cloete, N., Perold, H \& Papier, J. (2012). Shaping the future of South Africa's youth: Rethinking post-school education and skills training. Wynberg: African Minds

Dittmer, R. \& McFarland, S. (2007). 151 Quick ideas for delegating and decision making. Career Press: Franklin Lakes, NJ

Early, P. \& Fletcher-Campbell, F. (1998). The time to manage? Department and Faculty heads at work. Windsor: NFER-Nelson

Fernando, W, D, A. (2017). Advancing interests through informal voice: a study of professional workers in Sri Lanka's knowledge outsourcing sector. Human Resource Management Journal 24(4): 630-647. Doi: $10.111 / 1748-8583.12149$

Floyd, A. (2012). 'Turning points': The personal and professional circumstances that lead academics to become middle managers. Education Management Administration \& Leadership. 40(2): 272-284. Doi10.1177/1741143211427980

Gjerde, S., Alvesson, M. (2019). Sandwiched: Exploring role and identity of middle managers in the genuine middle. Human Relations. 73(1): 124-151. Doi:10.1177/0018726718823243

Gleeson, D. \& Knights, D. (2008). Reluctant leaders: An analysis of middle managers' perception of leadership in further education in England. Leadership. 4(1): 49 - 72

Gleeson, D. \& Shain, F. (1999). Managing ambiguity: between markets and managerialism - a case study of "middle managers" in further education. The sociological Review 47(3), 272-284

Glover, D., Miller, D., Gambling, M., Gough, G. \& Johnson, M. (1999). As other see us: senior management and subject staff perceptions of the work effectiveness of subject leaders in secondary schools. School leadership and Management 19, $331-358$

Graham, T. (2016). Role of academic managers in workload and performance management of academic staff: A case study. Educational Management Administration \& Leadership. 44(6): 1042-1063. Doi: $10.1177 / 1741143215587312$.

Harding, N., Lee, H. \& Ford, J. (2014). Who is "the middle manager"? Human Relations. 67(10): 1213-1237. Doi:10.1177/0018726713516654

Kraak, A., Paterson, A. \& Boka, K. (2016). Change management in TVET Colleges: Lessons learnt from the field of practice. Johannesburg: Jet Educational Services

Leithwood, K. \& Seashore-Louis, K. (2011). Linking leadership to student learning. New Jersey: John Wiley \& sons

Lumby, J. (2001). Managing Further Education Colleges: learning enterprise. London: Paul Chapman

Meek, V., Goedgebuure, L., Santiago, R., Carvalfo, T. (2010). The changing dynamics of Higher Education Middle Management. Springer: Springer

Raes, A. M. L., Heijltjes, M. G., Glunk, U. \& Roe, R. A. (2011). The interface of the top management team and middle managers: A process model. Academy of Management. 36(1): 102-126. Retrieved from https://www.jstor.org/stable/29765017

Rouleau, L. \& Balogun, J. (2011). Middle managers, strategic sense making and discursive competence. Journal of management studies. Doi:10.1111/j.1467-6486.2010.00941.x

Robertson, I. (2005). Coaching leadership: Building educational leadership capacity through coaching partnerships. Wellington: NZCER Press

Smart, J.K. (2003). Real delegation. How to get people to do the things for you and do them well. London: Pearson Education

Stronge, J., Richard, H. and Catano, N. (2008). Qualities of effective principals. Virginia: Association for Supervision and Curriculum Development

Tarakci, M., Ates, N. Y., Floyd, S. W., Ahn, Y. \& Woolridge, B. (2018). Performance feedback and middle managers' divergent strategic behaviour: The roles of social comparisons and organizational identification. (2018). Strategic Management Journal. 39: 1139-1162. Doi10.1002/smj.2745

Terblance, T. (2017). Technical and Vocational Education and Training (TVET Colleges in South Africa: A framework for leading curriculum change. Unpublished Ph.D. Thesis. Stellenbosch: Stellenbosch University.

Van der Westhuizen, A.J. (1998). An academic leadership model for transformation towards learning organisations in higher education. Unpublished Ph.D. Thesis. Stellenbosch: Stellenbosch University

Wellington, P. (2011). Effective people management: improve performance, delegate more effectively, handle poor performance and manage conflict. London: Kogan page

Wittman, R.G. \& Reuter, M.P. (2008). Strategic planning. How to deliver maximum value through effective 
business strategy. London: Kogan Page

Wootton, S. \& Horne, T. (2010). Strategic thinking. A nine step approach to strategy and leadership for managers and marketers. London: Kogan page 